\title{
Potential role for second-generation tyrosine kinase inhibitors in patients with chronic myeloid leukemia harboring additional clonal chromosome abnormalities: A retrospective CML Cooperative Study Group analysis
}

\author{
MAHO ISHIKAWA $^{1^{*}}$, NORIYOSHI IRIYAMA ${ }^{2 *}$, MICHIHIDE TOKUHIRA $^{3}$, TOMOIKU TAKAKU $^{4}$, ERIKO SATO $^{5}$, \\ KEI-JI SUGIMOTO ${ }^{6}$, TOMONORI NAKAZATO ${ }^{7}$, HIROYUKI FUJITA ${ }^{8}$, YUTA KIMURA $^{3}$, ISAO FUJIOKA ${ }^{4}$, \\ NORIO KOMATSU $^{4}$, NORIO ASOU ${ }^{1}$, MASAHIRO KIZAKI $^{3}$, YOSHIHIRO HATTA ${ }^{2}$ and TATSUYA KAWAGUCHI ${ }^{9,10}$ \\ ${ }^{1}$ Department of Hemato-Oncology, Saitama Medical University International \\ Medical Center, Saitama 350-1298; ${ }^{2}$ Division of Hematology and Rheumatology, Department of Medicine, \\ Nihon University School of Medicine, Tokyo $173-8610 ;{ }^{3}$ Department of Hematology, Saitama Medical Center, \\ Saitama Medical University, Saitama 350-8550; ${ }^{4}$ Department of Hematology, Juntendo University School of Medicine, \\ Tokyo 113-8431; ${ }^{5}$ Department of Hematology, Juntendo University Nerima Hospital, Tokyo 177-8521; \\ ${ }^{6}$ Department of Hematology, Juntendo University Urayasu Hospital, Chiba 279-0021; ${ }^{7}$ Department of Hematology, \\ Yokohama Municipal Citizen's Hospital, Kanagawa $240-8555 ;{ }^{8}$ Department of Hematology, \\ Saiseikai Yokohama Nanbu Hospital, Kanagawa 234-0054; ${ }^{9}$ Department of Hematology and Infectious Diseases, \\ Kumamoto University Hospital, Kumamoto 860-8556; ${ }^{10}$ Kumamoto Health Science University, Kumamoto 861-5598, Japan
}

Received May 8, 2019; Accepted August 29, 2019

DOI: 10.3892/or.2019.7339

\begin{abstract}
Tyrosine kinase inhibitor (TKI) treatment is the standard of care for patients with chronic myeloid leukemia (CML). Even in the imatinib era, the presence of 'clonal chromosomal abnormalities' in the Philadelphia chromosome $\left(\mathrm{CCA} / \mathrm{Ph}^{+}\right)$at diagnosis reportedly increased the risk of disease progression and predicted shorter survival. However, it remains unclear whether $\mathrm{CCA} / \mathrm{Ph}^{+}$is a poor prognostic marker in the era of new-generation TKIs. The data of patients with
\end{abstract}

Correspondence to: Dr Noriyoshi Iriyama, Division of Hematology and Rheumatology, Department of Medicine, Nihon University School of Medicine, 30-1 Oyaguchi Kami-cho, Itabashi-ku, Tokyo 173-8610, Japan

E-mail: iriyama.noriyoshi@nihon-u.ac.jp

${ }^{*}$ Contributed equally

Abbreviations: $\mathrm{CCA} / \mathrm{Ph}^{+}$, clonal chromosomal abnormalities in the Philadelphia chromosome; CCyR, complete cytogenetic response; CML, chronic myeloid leukemia; CP, chronic phase; DMR, deep molecular response; EFS, event-free survival; ELN, European LeukemiaNet; IS, International Scale; MMR, major molecular response; OS, overall survival; TKI, tyrosine kinase inhibitor; TMA, transcription-mediated amplification

Key words: chronic myeloid leukemia, Philadelphia chromosome, clonal chromosome abnormality, tyrosine kinase inhibitor, prognosis
CML in the chronic phase $(\mathrm{CP})$ that were extracted from the CML Cooperative Study Group database were retrospectively analyzed. Of the 328 eligible patients, $33(10.1 \%)$ had CCA/ $\mathrm{Ph}^{+}$, including 9 major route and 24 minor route aberrations. The characteristics of patients with and without $\mathrm{CCA} / \mathrm{Ph}^{+}$were similar; however, the proportion of blasts was higher among patients with $\mathrm{CCA} / \mathrm{Ph}^{+}$. Notably, the survival rate of patients with $\mathrm{CCA} / \mathrm{Ph}^{+}$was not inferior to that of patients without $\mathrm{CCA} / \mathrm{Ph}^{+}$, and there were no differences in responses to TKIs. All 9 patients with major route $\mathrm{CCA} / \mathrm{Ph}^{+}$attained a major molecular response (MMR) with no disease progression, and 8 ultimately achieved a deep molecular response. In particular, the median interval between TKI initiation and achievement of MMR was shorter in patients initially treated with a second-generation TKI than in those treated with imatinib (5 vs. 10 months). The present retrospective study, thus, revealed favorable treatment outcomes in CML-CP patients with $\mathrm{CCA} / \mathrm{Ph}^{+}$treated with second-generation TKIs. The data indicated that administering second-generation TKIs as first-line treatments is preferable in CML-CP patients with $\mathrm{CCA} / \mathrm{Ph}^{+}$.

\section{Introduction}

Chronic myeloid leukemia (CML) is a hematopoietic clonal disease characterized by the accumulation of myeloid lineage cells harboring the $B C R-A B L 1$ fusion gene, which results from the formation of the Philadelphia $(\mathrm{Ph})$ chromosome in hematopoietic stem cells. Although this disease is regarded as a life-threatening hematologic malignancy, the advent 
of tyrosine kinase inhibitors (TKIs) has revolutionized the management of patients with CML. The International Randomized Study of Interferon and STI571 trial conducted in chronic phase (CP) CML patients demonstrated excellent treatment responses and more durable remissions in patients treated with imatinib than in those who received the interferon- $\alpha$ plus cytarabine regimen (1). A recent long-term observation study also revealed that the 10 -year overall survival (OS) rate in its imatinib arm was $>80 \%$, with over half of the deaths in this arm due to reasons unrelated to CML (1). The efficacy of imatinib has also been demonstrated in Japanese patients $(2,3)$. Thus, imatinib therapy has become a standard of care for patients with CML. In the era of TKI, the OS rate in CML-CP patients who achieve complete cytogenetic response (CCyR) or better is similar to that in the general population (4). However, some patients remain refractory to this therapy and experience disease progression.

The existence of additional clonal chromosomal abnormalities in the $\mathrm{Ph}^{+}$cells $\left(\mathrm{CCA} / \mathrm{Ph}^{+}\right)$of patients with CML-CP at diagnosis is associated with poor prognosis, particularly in those with specific CCAs, referred to as 'major route abnormalities' in the pre-imatinib era. Such abnormalities include trisomy 8, +der(22)t(9;22)(q34;q11), isochromosome 17 (i(17) (q10)), trisomy 19, and ider(22)(q10)t(9;22)(q34;q11). The rare CCAs, such as trisomy $21, \mathrm{t}(3 ; 12), \mathrm{t}(4 ; 6), \mathrm{t}(2 ; 16)$, and $\mathrm{t}(1 ; 21)$, are designated 'minor route' CCAs (5-10). Notably, the clinical significance of harboring $\mathrm{CCA} / \mathrm{Ph}^{+}$has mostly been evaluated in patients treated with first-line imatinib (7-10). Patients with CML who concomitantly harbor these abnormalities are designated as possessing 'warning' criteria, according to the European LeukemiaNet (ELN) 2013 recommendations, and are, therefore, required to be monitored carefully (6). However, there are no recommended treatment guidelines for patients with these abnormalities.

Over the past decade, second-generation TKIs, such as nilotinib, dasatinib, and bosutinib, as well as the third-generation TKI, ponatinib, were developed for patients resistant or intolerant to prior TKI therapy. In addition to imatinib, second-generation TKIs, nilotinib and dasatinib, are now recommended as first-line therapies for patients with CML-CP according to the ELN 2013 recommendations, which were based on data from larger randomized studies $(6,11,12)$. Imatinib, nilotinib, and dasatinib are currently available as first-line treatments for patients with CML-CP in Japan. This warrants reevaluation of the impact of the presence of $\mathrm{CCA} / \mathrm{Ph}^{+}$on patient clinical outcomes in the era of second-generation TKIs.

In the present study, the treatment responses and outcomes of CML-CP patients with $\mathrm{CCA} / \mathrm{Ph}^{+}$treated with second-generation TKIs were investigated. The present data should help to devise current era TKI treatment regimens that are optimized according to cytogenetic risk stratification.

\section{Patients and methods}

Patients. The data of patients enrolled in the CML Cooperative Study Group (CML-CSG) database (original study has been reported in 2017 (13)), that encompassed 5 university hospitals (Saitama Medical University International Medical Center, Nihon University School of Medicine, Saitama Medical Center Saitama Medical University, Juntendo University
School of Medicine and Kumamoto University Hospital) and 4 university branch hospitals (Juntendo University Nerima Hospital, Juntendo University Urayasu Hospital, Yokohama Municipal Citizen's Hospital and Saiseikai Yokohama Nanbu Hospital) was analyzed. The study included patients diagnosed with CML-CP and treated with a TKI as first-line therapy. The diagnosis of CML-CP was based on the ELN criteria as previously described (6). Patients who had received interferon- $\alpha$ or any other chemotherapeutic agent for CML before TKI administration were excluded; however, the administration of hydroxyurea prior to TKI therapy for the purpose of reducing the number of leukocytes was allowed. Between April 2001 and January 2016, 369 patients newly diagnosed with a $\mathrm{Ph}$ chromosome and/or $B C R-A B L 1$ positive CML were registered in the CML-CSG database. The study was approved by the institutional review boards of all the above nine participating facilities and was conducted in accordance with the Declaration of Helsinki.

Cytogenetic studies. Results of cytogenetic bone marrow analyses obtained at the time of CML diagnosis were registered in the CML-CSG database. Twenty metaphases were routinely counted and analyzed in each patient according to the International System for Human Cytogenetic Nomenclature recommendations. Major route $\mathrm{CCA} / \mathrm{Ph}^{+}$was defined as $\mathrm{Ph}^{+}$ cells harboring trisomy $8,+\operatorname{der}(22) \mathrm{t}(9 ; 22)(\mathrm{q} 34 ; \mathrm{q} 11)$, isochromosome 17 (i(17)(q10)), trisomy 19, or ider(22)(q10)t(9;22) (q34;q11), and the minor route $\mathrm{CCA} / \mathrm{Ph}^{+}$was defined as $\mathrm{Ph}^{+}$ cells harboring rare abnormalities such as trisomy $21, \mathrm{t}(3 ; 12)$, $\mathrm{t}(4 ; 6), \mathrm{t}(2 ; 16), \mathrm{t}(1 ; 21),-Y$, a variant translocation $\mathrm{t}(\mathrm{v} ; 22)$, or other less common abnormalities. $\mathrm{CCA} / \mathrm{Ph}^{+}$detected in only 1 metaphase was not considered a clonal cytogenetic abnormality.

Molecular response assessment. The molecular response was assessed by quantifying the $B C R-A B L 1$ transcript using real-time quantitative PCR or a transcription-mediated amplification (TMA) and a hybridization protection assay $(14,15)$. $B C R-A B L 1$ transcript levels $\leq 0.1 \%$ according to the International Scale (IS) or $\leq 100$ copies $/ \mu \mathrm{g}$ RNA as determined using the TMA assay were considered a major molecular response (MMR), while $B C R-A B L 1$ IS transcript levels of $\leq 0.0032 \%$ were considered a deep molecular response (DMR), as previously described $(14,15)$.

Statistical analysis. Fisher's exact and Mann-Whitney U tests were used to determine statistically significant differences between the groups. Event-free survival (EFS) was defined as the period between the date of commencing treatment with TKI and the date of the first incidence of any event or the last follow-up. An event was defined as the loss of treatment efficacy after achieving complete hematologic response, partial cytogenetic response, or CCyR (6); progression to the accelerated or blast phase; or death from any cause. Treatment responses were assessed as the cumulative MMR or DMR achieved at each time-point, irrespective of switching TKIs. Univariate and multivariate analyses were performed to identify whether $\mathrm{CCA} / \mathrm{Ph}^{+}$had a negative impact on outcomes. The Sokal score, type of initial TKI (imatinib or second-generation TKIs), and presence of $\mathrm{CCA} / \mathrm{Ph}+$ were included in the analysis. A P-value of $<0.05$ was considered statistically significant. The statistical 

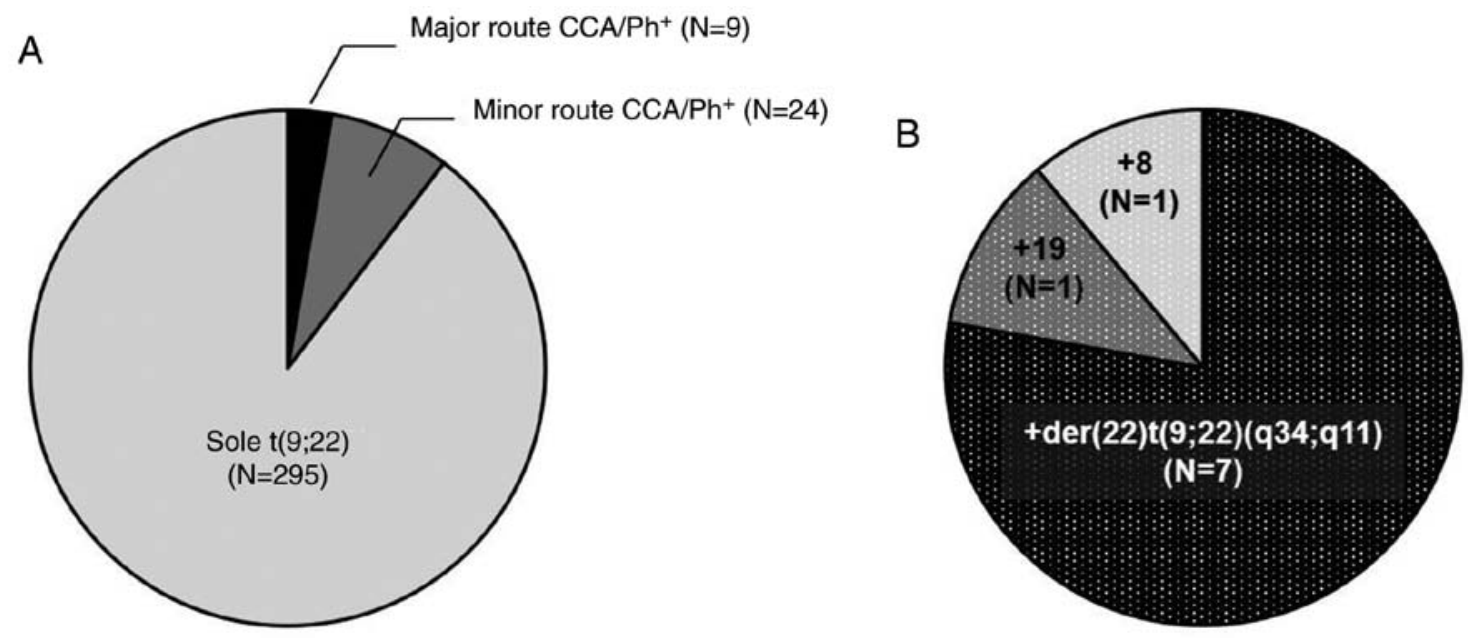

Figure 1. Patient distributions. (A) Cytogenetic subgroups of 328 eligible patients at diagnosis. Among these patients, $295(89.9 \%)$ had $\mathrm{t}(9 ; 22)(\mathrm{q} 34 ; \mathrm{q} 11)$ only and $33(10.1 \%)$ had CCA/ $\mathrm{Ph}^{+}$. Nine patients (2.7\%) had major route CCA $/ \mathrm{Ph}^{+}$and $24(7.3 \%)$ had minor route $\mathrm{CCA} / \mathrm{Ph}^{+}$. (B) The frequencies of major route clonal chromosome abnormalities in the Philadelphia chromosome. The $+\operatorname{der}(22) t(9 ; 22)(q 34 ; q 11)$ aberration was the most frequently observed in this study population.

analyses were performed using EZR (Saitama Medical Center, Jichi Medical University), a graphical user interface for the $\mathrm{R}$ programming language (The R Foundation for Statistical Computing) (16).

\section{Results}

Patient characteristics. Between April 2001 and January 2016, 369 patients newly diagnosed with a $\mathrm{Ph}$ chromosome and/or $B C R-A B L 1$ positive CML were registered in the CML-CSG database. Among these patients, 328 had data on their bone marrow chromosomal analyses at diagnosis, 9 were in the accelerated phase, and 32 lacked data for cytogenetic analysis (i.e., cryptic $\mathrm{Ph}$, insufficient number of mitotic cells obtained, or missing data altogether). Of the 328 eligible patients, 9 had major route $\mathrm{CCA} / \mathrm{Ph}^{+}$, including 7 with $+\operatorname{der}(22) \mathrm{t}(9 ; 22)$ (q34;q11), 1 with trisomy 19, and 1 with trisomy 8 , and 24 had minor route $\mathrm{CCA} / \mathrm{Ph}^{+}$(Fig. 1). The characteristics of patients with or without $\mathrm{CCA} / \mathrm{Ph}^{+}$at diagnosis are presented in Tables I and SI. There were no significant differences between the groups in terms of median patient age; platelet, leukocyte, eosinophil, and basophil counts; and spleen size. However, the proportion of blasts was higher in the $\mathrm{CCA} / \mathrm{Ph}^{+}$group. Risk stratification by the Sokal, Hasford, and European Treatment and Outcome Study (EUTOS) scoring systems were similar between the groups. Furthermore, the use of second-generation TKIs as the first-line therapies was equally distributed between the groups.

Treatment outcomes according to the CCA/Ph $h^{+}$status. The outcomes of patients with $\mathrm{CCA} / \mathrm{Ph}^{+}$were then investigated and compared to those of patients without additional aberrations. During the follow-up period, 36 events occurred and 24 patients (7.3\%) died. Among these 24, 8 (33.3\%) succumbed due to the progression of CML. With a median follow-up period of 66 months (range: 14-167 months) in patients with CCA/ $\mathrm{Ph}^{+}$and 67 months (range: 0-202 months) in those without CCA $/ \mathrm{Ph}^{+}, 5$-year EFS rates were $87.8 \%$ in the former group and $90.0 \%$ in the latter $(\mathrm{P}=0.482)$ (Fig. 2A).
Furthermore, 5-year OS rates were $87.9 \%$ in the former group and $93.7 \%$ in the latter $(\mathrm{P}=0.096)$ (Fig. 2B). Thus, the presence of $\mathrm{CCA} / \mathrm{Ph}^{+}$was not an adverse prognostic factor among our patients. Univariate and multivariate analyses revealed that EFS and OS were shorter in Sokal high-risk patients than in those considered to be low risk. The analysis confirmed that the presence of $\mathrm{CCA} / \mathrm{Ph}^{+}$in CML-CP was not a statistically significant adverse prognostic factor for EFS and OS in our cohort (Table II).

Treatment responses in patients with $\mathrm{CCA} / \mathrm{Ph}^{+}$. The responses to TKI therapy among patients with $\mathrm{CCA} / \mathrm{Ph}^{+}$ (Table III) were further investigated. Among the 33 patients with $\mathrm{CCA} / \mathrm{Ph}^{+}$, the 12 -month and overall MMR rates were 63.6 and $90.9 \%$, respectively, while the 24 -month and overall DMR rates were 15.2 and $57.6 \%$, respectively. Among the 295 patients without $\mathrm{CCA} / \mathrm{Ph}^{+}$, the 12 -month and overall MMR rates were 51.2 and $89.8 \%$, respectively, and the 24-month and overall DMR rates were 15.6 and 57.6\%, respectively. None of the differences were statistically significant, suggesting that the presence of CCA $/ \mathrm{Ph}^{+}$did not affect the response to TKI therapy.

Treatment responses and prognoses in patients with major route $C C A / P h^{+}$. Finally, it was investigated whether major route $\mathrm{CCA} / \mathrm{Ph}^{+}$affected the clinical outcomes of these patients given that the presence of this abnormality at diagnosis is a critical adverse prognostic factor in patients treated with first-line imatinib $(7,10)$. Table IV presents the characteristics and treatment response of the 9 patients with major route and 33 patients with minor route $\mathrm{CCA} / \mathrm{Ph}^{+}$, respectively, their treatment regimens, best responses to TKI, and outcomes. With respect to initial therapy, in major route $\mathrm{CCA} / \mathrm{Ph}^{+}$, 5 patients were treated with imatinib, 3 with nilotinib, and 1 with dasatinib; none experienced disease progression, and all are alive at the date of the writing of this manuscript. All 9 attained an MMR and retained the therapeutic benefit of TKI, and 8 attained a DMR during the observation period. Notably, treatment with second-generation TKIs resulted in 
Table I. Baseline characteristics of patients before treatment according to cytogenetic abnormality.

\begin{tabular}{|c|c|c|c|}
\hline Factors & With CCA/Ph ${ }^{+}(\mathrm{N}=33)$ & Only $\mathrm{t}(9 ; 22)(\mathrm{N}=295)$ & P-value \\
\hline Age (years), median (range) & $51(24-82)$ & $53(18-86)$ & 0.508 \\
\hline Sex male, n (\%) & $23(70)$ & $176(60)$ & 0.348 \\
\hline Hemoglobin (g/dl), median (range) & $13.0(8.4-15.6)$ & $13.0(5.0-18.8)$ & 0.932 \\
\hline Platelet number $\left(\times 10^{9} / 1\right)$, median (range) & $463(115-3,417)$ & $512(86-4,352)^{\mathrm{a}}$ & 0.382 \\
\hline Leukocyte number $\left(\mathrm{x} 10^{9} / 1\right)$, median (range) & $39.1(13.2-215.9)$ & $34.1(5.2-719.8)$ & 0.927 \\
\hline Eosinophils (\%), median (range) & $2.0(0-20.0)$ & $2.0(0-24.0)$ & 0.688 \\
\hline Basophils (\%), median (range) & $5.0(0-17.0)$ & $5.0(0-19.5)$ & 0.708 \\
\hline Blasts $(\%)$, median (range) & $0.5(0-13.5)$ & $0(0-13.0)$ & 0.028 \\
\hline Spleen size $(\mathrm{cm})$, median (range) & $0(0-20)$ & $0(0-27)$ & 0.106 \\
\hline \multicolumn{4}{|l|}{ Sokal scoring system, n (\%) } \\
\hline Low & $15(45)$ & $122(41)$ & \multirow[t]{3}{*}{0.824} \\
\hline Intermediate & $10(30)$ & $107(36)$ & \\
\hline High & $6(18)$ & $49(17)$ & \\
\hline \multicolumn{4}{|l|}{ Hasford scoring system, n (\%) } \\
\hline Low & $14(42)$ & $115(39)$ & \multirow[t]{3}{*}{0.650} \\
\hline Intermediate & $13(39)$ & $135(46)$ & \\
\hline High & $4(12)$ & $28(9)$ & \\
\hline \multicolumn{4}{|l|}{ EUTOS scoring system, n (\%) } \\
\hline Low & $24(73)$ & $239(81)$ & \multirow[t]{3}{*}{0.193} \\
\hline High & $7(21)$ & $39(13)$ & \\
\hline Scoring unknown, n (\%) & $2(6)$ & $17(6)$ & \\
\hline \multicolumn{4}{|l|}{ Initial TKI, n (\%) } \\
\hline Imatinib & $18(55)$ & $154(52)$ & \multirow[t]{3}{*}{0.395} \\
\hline Dasatinib & $6(18)$ & $82(28)$ & \\
\hline Nilotinib & $9(27)$ & $59(20)$ & \\
\hline
\end{tabular}

${ }^{\text {aSole }} \mathrm{t}(9 ; 22)$ group included one patient who had platelet depletion $\left(<100 \times 10^{9} / 1\right)$ due to liver cirrhosis. CCA/Ph ${ }^{+}$, clonal chromosome abnormality in Philadelphia chromosome positive cells; EUTOS, European Treatment and Outcome Study.
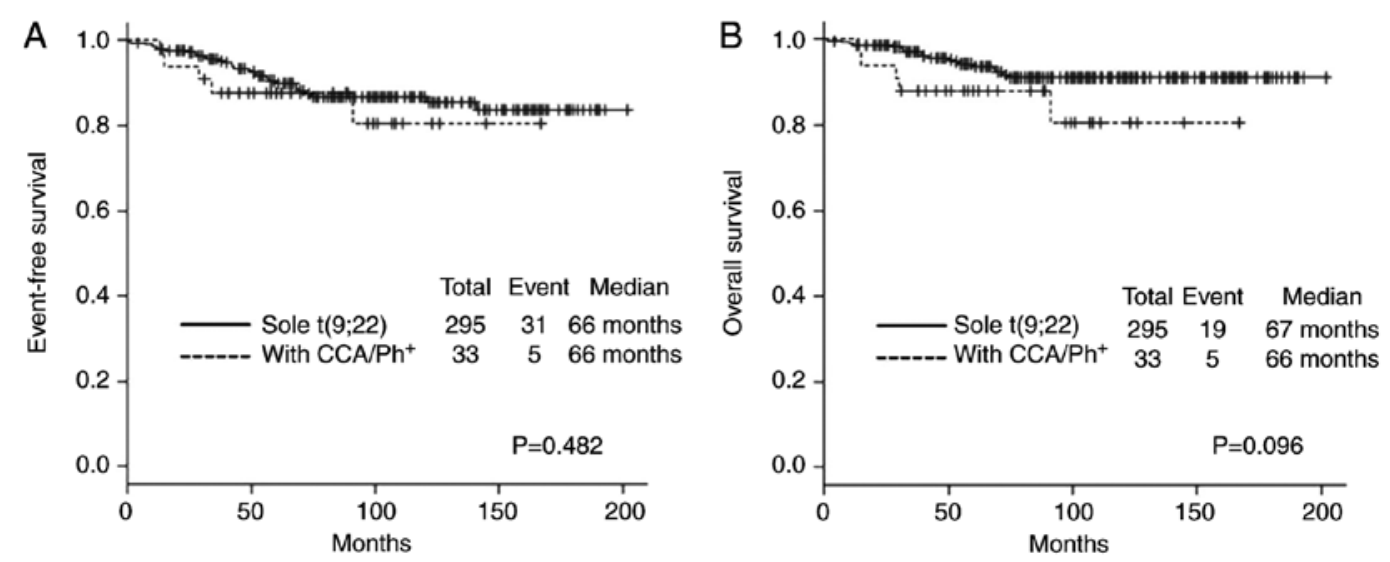

Figure 2. Kaplan-Meier curves of (A) event-free survival and (B) overall survival in patients with t(9;22) only (solid line) and clonal chromosome abnormalities in the Philadelphia chromosome $\left(\mathrm{CCA} / \mathrm{Ph}^{+}\right)$(dotted line).

an excellent treatment response; all 4 patients initially treated with nilotinib or dasatinib achieved MMR within 12 months, which is considered an optimal response according to the ELN 2013 recommendations (6). The duration between TKI initiation and the achievement of MMR was shorter in the second-generation TKI-treated group than in the imatinib-treated group (median, 5 vs. 10 months) in major route $\mathrm{CCA} / \mathrm{Ph}^{+}$. All 3 patients in minor route $\mathrm{CCA} / \mathrm{Ph}^{+}$ who were unable to achieve MMR experienced disease progression later. 
Table II. Analysis of the risk factors associated with the EFS and the OS.

\begin{tabular}{|c|c|c|c|c|}
\hline \multirow[b]{2}{*}{ Factor } & \multicolumn{2}{|c|}{ Univariate } & \multicolumn{2}{|c|}{ Multivariate } \\
\hline & $\mathrm{HR}(95 \% \mathrm{CI})$ & P-value & $\mathrm{HR}(95 \% \mathrm{CI})$ & P-value \\
\hline \multicolumn{5}{|l|}{ EFS } \\
\hline Sokal high vs. others & $2.24(1.07-4.70)$ & 0.032 & $2.26(1.08-4.72)$ & 0.043 \\
\hline Initial TKI imatinib vs. others & $0.69(0.33-1.41)$ & 0.307 & $0.62(0.30-1.31)$ & 0.210 \\
\hline With CCA/ $\mathrm{Ph}^{+}$vs. others & $1.40(0.54-3.61)$ & 0.485 & $1.55(0.60-4.02)$ & 0.365 \\
\hline \multicolumn{5}{|l|}{ OS } \\
\hline Sokal high vs. others & $3.06(1.28-7.31)$ & 0.012 & $3.09(1.29-7.36)$ & 0.011 \\
\hline Initial TKI imatinib vs. others & $0.78(0.33-1.88)$ & 0.587 & $0.68(0.27-1.69)$ & 0.405 \\
\hline With CCA/ $\mathrm{Ph}^{+}$vs. others & $2.26(0.84-6.04)$ & 0.106 & $2.64(0.97-7.16)$ & 0.057 \\
\hline
\end{tabular}

EFS, event free survival; OS, overall survival; HR, hazard ratio; CI, confidence interval; vs., versus; $\mathrm{CCA} / \mathrm{Ph}^{+}$, clonal chromosome abnormality in Philadelphia chromosome positive cells; TKI, tyrosine kinase inhibitor.

Table III. Outcome of patients according to $\mathrm{CCA} / \mathrm{Ph}^{+}$status.

$\begin{array}{ccc}\text { With } & \text { Only } & \\ \mathrm{CCA} / \mathrm{Ph}^{+} & \mathrm{t}(9 ; 22) & \\ (\mathrm{N}=33) & (\mathrm{N}=295) & \text { P-value }\end{array}$

\begin{tabular}{lccc}
\hline $\begin{array}{l}\text { Cumulative MMR rate (\%) } \\
\text { 12 months }\end{array}$ & 63.6 & 51.2 & 0.201 \\
$\quad$ Overall & 90.9 & 89.8 & 1.000 \\
$\quad$ Cumulative DMR rate (\%) & & & \\
$\quad 24$ months & 15.2 & 15.6 & 1.000 \\
$\quad$ Overall & 57.6 & 57.6 & 1.000 \\
Events & & & \\
$\quad$ Loss of treatment efficacy (\%) & 9.1 & 5.8 & 0.438 \\
$\quad$ Progression to AP/BP (\%) & 9.1 & 2.4 & 0.068 \\
$\quad$ Death (\%) & 15.2 & 6.4 & 0.079 \\
$\quad$ Related to CML, n & 3 & 5 & \\
$\quad$ Unrelated to CML, n & 2 & 14 & \\
HSCT (\%) & 3.0 & 1.0 & 0.347 \\
Secondary malignancies (\%) & 12.1 & 5.1 & 0.111 \\
\hline
\end{tabular}

$\mathrm{CCA} / \mathrm{Ph}^{+}$, clonal chromosome abnormality in Philadelphia chromosome positive cells; MMR, major molecular response; DMR, deep molecular response (MR4.5); AP, accelerated phase; BP, blast phase; CML, chronic myeloid leukemia; HSCT, hematopoietic stem cell transplantation.

\section{Discussion}

To date, studies on the relationship between the CCA/ $\mathrm{Ph}^{+}$ status and treatment outcome have mostly been conducted in patients treated with the first-in-class TKI imatinib. Because little is known regarding the impact of the presence of $\mathrm{CCA} / \mathrm{Ph}^{+}$at diagnosis on clinical outcomes in the current era of new-generation TKIs, the present study aimed to address this gap in knowledge using the CML-CSG database. It also focused on whether major route $\mathrm{CCA} / \mathrm{Ph}^{+}$remains an adverse prognostic factor in the era of newer TKIs. The present results revealed no evident differences in EFS and OS between patients with and without $\mathrm{CCA} / \mathrm{Ph}^{+}$. In the entire cohort, only 4 patients received allogeneic stem cell transplantation, including 3 in $\mathrm{CP}$ ( 2 in $\mathrm{CP} 1$ and 1 in CP2) and one after blastic transformation; the last case had $\mathrm{CCA} / \mathrm{Ph}^{+}$at initial diagnosis. During the follow-up period, 24 patients (7.3\%) died. Among them, 8 (33.3\%) succumbed to progression of CML, $2(8.3 \%)$ of secondary malignancies (lung cancer, rectal cancer), 2 of congestive heart failure, $1(4.2 \%)$ of synchronous pancreatic cancer, 1 from cardiopulmonary arrest on arrival suspected to be due to a cardiovascular event, 1 from suicide, and 9 (37.5\%) from unknown causes. Twenty patients experienced loss of treatment efficacy, 3 of whom had CCA/Ph+; 10 of these patients progressed to accelerated or blast phase, 3 of whom had $\mathrm{CCA} / \mathrm{Ph}^{+}$. With respect to the secondary malignancies, the sites included stomach $(\mathrm{N}=4)$ and colorectal $(\mathrm{N}=3)$, with oral, tongue, larynx, esophagus, breast, lung, liver, gallbladder, renal pelvis, prostate, ovary, and malignant lymphoma accounting for the remaining 12 . We have already evaluated and published the incidence of secondary malignancies in our CML-CSG cohort (17). It is of interest that cumulative incidences of secondary malignancies in our findings are consistent with those observed in a recent study (18). In terms of the treatment responses in patients with major route $\mathrm{CCA} / \mathrm{Ph}^{+}$, the achievement of MMR (a critical determinant of patient prognosis) occurred earlier in those treated with second-generation TKIs than in those treated with imatinib. Treatment responses in patients with $\mathrm{CCA} / \mathrm{Ph}^{+}$demonstrated that the achievement of MMR within 12 months has a tendency to sustain DMR later, as previously reported (19). Although this study population included 113 patients who were diagnosed before the approval of the second-generation TKIs in March 2009, all but 8 were followed until approval for nilotinib/dasatinib or thereafter. Moreover, nearly half of our study's cohort was initially treated with the second-generation TKIs nilotinib or dasatinib. It should thus be noted that the outcomes obtained in our study population reflected the use of various TKIs. We have recently revealed that the EUTOS score was the most 
Table IV. Characteristics and treatment response in patients with $\mathrm{CCA} / \mathrm{Ph}^{+}$.

\begin{tabular}{|c|c|c|c|c|c|c|c|c|}
\hline \multirow{2}{*}{$\begin{array}{l}\text { Age } \\
\text { (years) }\end{array}$} & \multirow[b]{2}{*}{ Sex } & \multirow[b]{2}{*}{ Subgroup of CCA/Ph+ } & \multirow{2}{*}{$\begin{array}{l}\text { Initial TKI } \\
\text { (mg/day) }\end{array}$} & \multirow{2}{*}{$\begin{array}{c}\text { MMR } \\
\text { (months) }\end{array}$} & \multicolumn{3}{|c|}{ Best response } & \multirow{2}{*}{$\begin{array}{c}\text { Disease } \\
\text { progression }\end{array}$} \\
\hline & & & & & CCyR & MMR & DMR & \\
\hline 45 & $\mathrm{~F}$ & trisomy 19 & Imatinib 400 & 22 & $\sqrt{ }$ & $\sqrt{ }$ & $\sqrt{ }$ & No \\
\hline 64 & $\mathrm{~F}$ & $+\operatorname{der}(22) \mathrm{t}(9 ; 22)(\mathrm{q} 34 ; \mathrm{q} 11)$ & Imatinib 400 & 10 & $\sqrt{ }$ & $\sqrt{ }$ & $\sqrt{ }$ & No \\
\hline 49 & M & trisomy 8 & Imatinib 400 & 6 & $\sqrt{ }$ & $\sqrt{ }$ & $\sqrt{ }$ & No \\
\hline 51 & M & $+\operatorname{der}(22) \mathrm{t}(9 ; 22)(\mathrm{q} 34 ; \mathrm{q} 11)$ & Imatinib 400 & 5 & $\sqrt{ }$ & $\sqrt{ }$ & $\sqrt{ }$ & No \\
\hline 40 & $\mathrm{M}$ & $+\operatorname{der}(22) \mathrm{t}(9 ; 22)(\mathrm{q} 34 ; \mathrm{q} 11)$ & Imatinib 400 & 14 & $\sqrt{ }$ & $\sqrt{ }$ & $\sqrt{ }$ & No \\
\hline 73 & $\mathrm{~F}$ & $+\operatorname{der}(22) \mathrm{t}(9 ; 22)(\mathrm{q} 34 ; \mathrm{q} 11)$ & Dasatinib 100 & 3 & $\sqrt{ }$ & $\sqrt{ }$ & $\sqrt{ }$ & No \\
\hline 38 & $\mathrm{~F}$ & $+\operatorname{der}(22) \mathrm{t}(9 ; 22)(\mathrm{q} 34 ; \mathrm{q} 11)$ & Nilotinib 600 & 6 & $\sqrt{ }$ & $\sqrt{ }$ & & No \\
\hline 72 & $\mathrm{~F}$ & $+\operatorname{der}(22) \mathrm{t}(9 ; 22)(\mathrm{q} 34 ; \mathrm{q} 11)$ & Nilotinib 300 & 3 & $\sqrt{ }$ & $\sqrt{ }$ & $\sqrt{ }$ & No \\
\hline 50 & M & $+\operatorname{der}(22) \mathrm{t}(9 ; 22)(\mathrm{q} 34 ; \mathrm{q} 11)$ & Nilotinib 600 & 7 & $\sqrt{ }$ & $\sqrt{ }$ & $\sqrt{ }$ & No \\
\hline 69 & M & $\begin{array}{l}\mathrm{t}(\mathrm{X} ; 9 ; 22 ; 26) \\
(\mathrm{p} 11.2 ; \mathrm{q} 34 ; \mathrm{q} 11.2 ; \mathrm{p} 13.3)\end{array}$ & Imatinib 300 & 5 & $\sqrt{ }$ & $\sqrt{ }$ & $\sqrt{ }$ & No \\
\hline 79 & M & $\operatorname{inv}(8)(p 21 q 22)$ & Imatinib 300 & 45 & $\sqrt{ }$ & $\sqrt{ }$ & & No \\
\hline 82 & M & $-14, \operatorname{del}(22)(q 13)$ & Imatinib 400 & 37 & $\sqrt{ }$ & $\sqrt{ }$ & & No \\
\hline 52 & $\mathrm{M}$ & $\mathrm{t}(9 ; 22 ; 12)(\mathrm{q} 34 ; \mathrm{q} 11 ; \mathrm{p} 13)$ & Imatinib 400 & 6 & $\sqrt{ }$ & $\sqrt{ }$ & $\sqrt{ }$ & No \\
\hline 69 & M & $\mathrm{t}(3 ; 9 ; 22)((\mathrm{q} 21 ; \mathrm{q} 34 ; \mathrm{q} 11.2)$ & Imatinib 400 & 3 & $\sqrt{ }$ & $\sqrt{ }$ & & No \\
\hline 38 & M & $\mathrm{t}(8 ; 9 ; 22)(\mathrm{q} 24+\mathrm{q} 24+11.2)$ & Imatinib 400 & 7 & $\sqrt{ }$ & $\sqrt{ }$ & & No \\
\hline 43 & M & $\mathrm{t}(8 ; 12)(\mathrm{p} 21: \mathrm{p} 13)$ & Imatinib 400 & NR & $\sqrt{ }$ & & & Yes \\
\hline 24 & M & $\begin{array}{l}\mathrm{t}(3 ; 12)(\mathrm{q} 12 ; \mathrm{q} 13), \mathrm{t}(4 ; 5) \\
(\mathrm{p} 34 ; \mathrm{p} 15), \operatorname{add}(9)(\mathrm{q} 34) \\
\mathrm{t}(9 ; 22 ; 12)(\mathrm{q} 34 ; \mathrm{q} 11 ; \mathrm{p} 13)\end{array}$ & Imatinib 400 & NR & $\sqrt{ }$ & & & Yes \\
\hline 48 & M & $\mathrm{t}(9 ; 22 ; 11)(\mathrm{q} 34 ; \mathrm{q} 11.2 ; \mathrm{q} 13)$ & Imatinib 400 & 19 & $\sqrt{ }$ & $\sqrt{ }$ & $\sqrt{ }$ & No \\
\hline 69 & M & $\mathrm{t}(5 ; 7)(\mathrm{q} 35 ; \mathrm{q} 11.2)$ & Imatinib 400 & 82 & $\sqrt{ }$ & $\sqrt{ }$ & & No \\
\hline 39 & $\mathrm{~F}$ & $\begin{array}{l}\operatorname{inv}(9)(\mathrm{p} 12 \mathrm{q} 13), \mathrm{t}(9 ; 22 ; 14) \\
(\mathrm{q} 34 ; \mathrm{q} 11.2 ; \mathrm{q} 11.2)\end{array}$ & Imatinib 400 & 10 & $\sqrt{ }$ & $\sqrt{ }$ & $\sqrt{ }$ & No \\
\hline 82 & $\mathrm{~F}$ & $-X$ & Imatinib 400 & 6 & $\sqrt{ }$ & $\sqrt{ }$ & $\sqrt{ }$ & No \\
\hline 34 & $\mathrm{~F}$ & $\mathrm{t}(9 ; 22 ; 21)(\mathrm{q} 34 ; \mathrm{q} 11.2 ; \mathrm{q} 22)$ & Imatinib 400 & 5 & $\sqrt{ }$ & $\sqrt{ }$ & $\sqrt{ }$ & No \\
\hline 64 & M & $\mathrm{t}(9 ; 22 ; 14)(\mathrm{q} 34 ; \mathrm{q} 11.2 ; \mathrm{q} 32)$ & Dasatinib 50 & 8 & $\sqrt{ }$ & $\sqrt{ }$ & & No \\
\hline 64 & M & $-\mathrm{Y}$ & Dasatinib 100 & 2 & $\sqrt{ }$ & $\sqrt{ }$ & $\sqrt{ }$ & No \\
\hline 72 & M & $\operatorname{inv}(3)(\mathrm{p} 13 \mathrm{q} 27)$ & Dasatinib 100 & 11 & $\sqrt{ }$ & $\sqrt{ }$ & & No \\
\hline 50 & M & $\mathrm{t}(6 ; 9 ; 22)(\mathrm{p} 21 ; \mathrm{q} 34 ; \mathrm{q} 11.2)$ & Dasatinib 100 & 4 & $\sqrt{ }$ & $\sqrt{ }$ & $\sqrt{ }$ & No \\
\hline 79 & M & $-Y$ & Dasatinib 140 & NR & $\sqrt{ }$ & & & Yes \\
\hline 51 & $\mathrm{~F}$ & $\mathrm{t}(9 ; 22 ; 15)(\mathrm{q} 34 ; \mathrm{q} 11.2 ; \mathrm{q} 24)$ & Nilotinib 300 & 6 & $\sqrt{ }$ & $\sqrt{ }$ & & No \\
\hline 24 & M & $\operatorname{del}(9)(\mathrm{q} ?), \operatorname{add}(10)(\mathrm{p} 11,2)$ & Nilotinib 600 & 38 & $\sqrt{ }$ & $\sqrt{ }$ & & No \\
\hline 31 & M & $\mathrm{t}(9 ; 22 ; 17)(\mathrm{q} 34: \mathrm{q} 11.2: \mathrm{p} 13)$ & Nilotinib 600 & 6 & $\sqrt{ }$ & $\sqrt{ }$ & $\sqrt{ }$ & No \\
\hline 65 & M & $-\mathrm{Y}$ & Nilotinib 600 & 45 & $\sqrt{ }$ & $\sqrt{ }$ & & No \\
\hline 49 & M & $\mathrm{t}(8 ; 10)(\mathrm{p} 10 ; \mathrm{p} 10)$ & Nilotinib 600 & 23 & $\sqrt{ }$ & $\sqrt{ }$ & $\sqrt{ }$ & No \\
\hline 42 & $\mathrm{~F}$ & $\begin{array}{l}\operatorname{add}(3)(q 21), \operatorname{der}(9), \\
\operatorname{add}(22)(q 11.2)\end{array}$ & Nilotinib 600 & 6 & $\sqrt{ }$ & $\sqrt{ }$ & $\sqrt{ }$ & No \\
\hline
\end{tabular}

Major route $\mathrm{CCA} / \mathrm{Ph}^{+}$cases are presented between the top and the 9 th row, and minor route $\mathrm{CCA} / \mathrm{Ph}^{+}$cases follow below. Best response column filled with $\sqrt{ }$ indicates the achievement of CCyR, MMR, or DMR in each patient. CCA/ $\mathrm{Ph}^{+}$, clonal chromosome abnormality in Philadelphia chromosome positive cells; TKI, tyrosine kinase inhibitor; M, male; F, female; NR, not reached; CCyR, complete cytogenetic response; MMR, major molecular response; DMR, deep molecular response (MR4.5).

predictive factor for the outcomes of patients among three scoring systems (Sokal, Hasford, or EUTOS), however, the use of second-generation TKIs could overcome the impact of EUTOS high-risk scores (20).

Previous studies conducted with imatinib revealed that the presence of $\mathrm{CCA} / \mathrm{Ph}^{+}$at diagnosis was an adverse prognostic factor in patients with CML-CP $(7,8)$. The overall MMR rate was also reported to be lower in patients with $\mathrm{CCA} / \mathrm{Ph}^{+}$than in those without $\mathrm{CCA} / \mathrm{Ph}^{+}(7,8)$. Moreover, based on the data of 1,151 patients enrolled in the German CML-Study IV who received first-line imatinib therapy, those with major route $\mathrm{CCA} / \mathrm{Ph}^{+}$had significantly poorer prognoses than those with 
$\mathrm{t}(9 ; 22)$ only, although those with minor route $\mathrm{CCA} / \mathrm{Ph}+\mathrm{did}$ not (7). Based on these data, the ELN 2013 recommendations defined major route $\mathrm{CCA} / \mathrm{Ph}^{+}$at baseline as a 'warning' criterion and regarded the emergence of $\mathrm{CCA} / \mathrm{Ph}^{+}$during treatment as 'failure' (6). Therefore, close observation and early intervention were warranted for patients with major route $\mathrm{CCA} / \mathrm{Ph}^{+}$at diagnosis during the imatinib era (7). In contrast to these collective data, the latest investigation of the clinical significance of major route $\mathrm{CCA} / \mathrm{Ph}^{+}$at diagnosis revealed that the abnormality had no impact on prognosis, which is consistent with our results (21). Notably, that study consisted of 603 patients from the MD Anderson Cancer Center, among whom 324 were initially treated with new-generation TKIs and 207 received high-dose imatinib (21). The discrepancy between the results of recent studies and older ones is presumably due to the different treatment modalities used for each lesion or in each institution. Thus, recent data indicated that the use of new-generation TKIs may overcome the adverse impact of $\mathrm{CCA} / \mathrm{Ph}^{+}$at diagnosis. Imatinib, nilotinib, and dasatinib are equally recommended as the first-line therapy for CML-CP according to the ELN2013 recommendations. Noatbly, the majority of newly diagnosed patients with CML are now initially treated with the second-generation TKIs nilotinib or dasatinib in Japan. Although the present study demonstrated that second-generation TKIs effectively induced faster and deeper molecular responses even in patients with $\mathrm{CCA} / \mathrm{Ph}^{+}$, the benefits and risks for the use of second-generation TKIs should be carefully taken into consideration. In fact, our previous study revealed the frequent incidence of vascular adverse events from treatment with second-generation TKIs (22). These benefits and risks should be investigated in a large well-designed study population.

Although the etiology of $\mathrm{CCA} / \mathrm{Ph}^{+}$is uncertain, a higher proportion of blasts was observed in the peripheral blood of patients with CCA/Ph than in those without $\mathrm{CCA} / \mathrm{Ph}^{+}$, which may reflect the aggressive character of the disease. Some evidence suggests that the structural alteration of the chromosome is closely linked to an increase in genomic instability $(23,24)$. Not only could the numerical chromosomal abnormalities be detected using standard cytogenetic analysis but also multiple genetic aberrations were discovered in patients with CML-CP using sensitive genomic hybridization and single-nucleotide polymorphism analysis (25). The accumulation of these additional genetic aberrations represents an underlying genomic instability and has a detrimental effect on the maintenance of normal cell physiology, which may explain why the use of TKIs with more potent and/or broad tyrosine kinase inhibitory activity is beneficial for patients with $\mathrm{CCA} / \mathrm{Ph}^{+}$.

There were some limitations in the present study. Results of chromosomal analysis of the bone marrow at diagnosis were only available for 328 of the 360 patients with CML-CP registered in the CML-CSG database; the unavailability of data from 32 patients may have skewed our findings. Moreover, the results of chromosomal analyses were reported from each institution without central review; therefore, a lack of interobserver uniformity may exist. There may be some bias that could have resulted in the underestimation of molecular response rates because molecular evaluations were unavailable in some patients. Furthermore, the treatment strategy mainly depended on the decisions of the physicians, which may have led to varying doses and treatment optimizations for each type of
TKI. Thus, the switch to a different TKI and the loss of molecular response were not considered as an event in the present study, in accordance with most pivotal studies. TKI discontinuation is not recommended in the clinical setting according to the guidelines for CML in Japan; therefore, this study did not include analysis for TKI discontinuation. A large-scale observation study for TKI discontinuation is currently planned by the Japanese Society of Hematology Committee, and outcomes for TKI discontinuation in our database are going to be united. Whether the presence of CCA/ $\mathrm{Ph}^{+}$affects the result of TKI discontinuation will be clarified in the future.

In conclusion, the study revealed no clinical differences in treatment responses and outcomes between patients with and without $\mathrm{CCA} / \mathrm{Ph}^{+}$in the era of second-generation TKIs. The accumulation of more evidence regarding the prognostic significance of patients with major route $\mathrm{CCA} / \mathrm{Ph}^{+}$in the era of newer TKIs will provide helpful information on treatment strategies for patients with this abnormality. Since the proportion of patients with $\mathrm{CCA} / \mathrm{Ph}^{+}$in the present study was relatively small, the findings should be validated in larger and well-established populations.

\section{Acknowledgements}

Not applicable.

\section{Funding}

Funding information is not applicable.

\section{Availability of data and materials}

All data generated or analyzed during this study are included in this published article. The datasets used and/or analyzed during the current study are available from the corresponding author on reasonable request.

\section{Authors' contributions}

TK, MT, MI, and NI conceived and designed the study. MI and NI contributed to analysis and interpretation of data and wrote the manuscript. All other authors contributed to data collection and interpretation and have read and approved the final manuscript.

\section{Ethics approval and consent to participate}

All procedures performed in studies involving human participants were in accordance with the ethical standards of the institutional review board of all participating facilities and with the 1964 Helsinki declaration and its later amendments or comparable ethical standards. The approval number of the institutional review board of Saitama Medical Center, Saitama Medical University; as representative facility, is No. 1348, January 2016.

\section{Patient consent for publication}

The requirement for informed consent was not applicable owing to the study's retrospective nature. 


\section{Competing interests}

NI received honoraria and speaker fees from Bristol-Myers Squibb, Novartis Pharma K.K., Otsuka Pharmaceutical, and Pfizer Inc. MT received honoraria and speaker fees from Pfizer Inc. and Bristol-Myers Squibb. MK received honoraria and speaker fees from Bristol-Myers Squibb and Novartis Pharma K.K. TT and YH received honoraria from Bristol-Myers Squibb and Novartis Pharma K.K. TK received honoraria and speaker fees from Bristol-Myers Squibb, Novartis Pharma K.K., and Pfizer Inc. The remaining authors declare no competing financial interests. None of the authors have non-financial conflicts of interest to declare.

\section{References}

1. Hochhaus A, Larson RA, Guilhot F, Radich JP, Branford S, Hughes TP, Baccarani M, Deininger MW, Cervantes F, Fujihara S, et al: Long-term outcomes of imatinib treatment for chronic myeloid leukemia. N Engl J Med 376: 917-927, 2017.

2. Kizaki M, Takahashi N, Iriyama N, Okamoto S, Ono T, Usui N, Inokuchi K, Nakaseko C, Kurokawa M, Sumi M, et al: Efficacy and safety of tyrosine kinase inhibitors for newly diagnosed chronic-phase chronic myeloid leukemia over a 5-year period: Results from the Japanese registry obtained by the New TARGET system. Int J Hematol 109: 426-439, 2019.

3. Tauchi T, Kizaki M, Okamoto S, Tanaka H, Tanimoto M, Inokuchi K, Murayama T, Saburi Y, Hino M, Tsudo M, et al: Seven-year follow-up of patients receiving imatinib for the treatment of newly diagnosed chronic myelogenous leukemia by the TARGET system. Leuk Res 35: 585-590, 2011.

4. Sasaki K, Strom SS, O'Brien S, Jabbour E, Ravandi F, Konopleva M, Borthakur G, Pemmaraju N, Daver N, Jain P, et al: Prospective analysis: Relative survival in patients with chronic myeloid leukemia in chronic phase in the era of tyrosine kinase inhibitors. Lancet Haematol 5: e186-e193, 2015.

5. Mitelman F: The cytogenetic scenario of chronic myeloid leukemia. Leuk Lymphoma 11: (Suppl 1): S11-S15, 1993.

6. Baccarani M, Deininger MW, Rosti G, Hochhaus A, Soverini S, Apperley JF, Cervantes F, Clark RE, Cortes JE, Guilhot F, et al: European LeukemiaNet recommendations for the management of chronic myeloid leukemia: 2013. Blood 122: 872-884, 2013.

7. Fabarius A, Leitner A, Hochhaus A, Müller MC, Hanfstein B, Haferlach C, Göhring G, Schlegelberger B, Jotterand M, Reiter A, et al: Impact of additional cytogenetic aberrations at diagnosis on prognosis of CML: long-term observation of 1,151 patients from the randomized CML study IV. Blood 118: 6760-6768, 2011.

8. Luatti S, Castagnetti F, Marzocchi G, Baldazzi C, Gugliotta G, Iacobucci I, Specchia G, Zanatta L, Rege-Cambrin G, Mancini M, et al: Additional chromosomal abnormalities in Philadelphia-positive clone: Adverse prognostic influence on frontline imatinib therapy: A GIMEMA Working Party on CML analysis. Blood 120: 761-767, 2012.

9. Lee SE, Choi SY, Bang JH, Kim SH, Jang EJ, Byeun JY, Park JE, Jeon HR, Oh YJ, Kim M and Kim DW: The long-term clinical implications of clonal chromosomal abnormalities in newly diagnosed chronic phase chronic myeloid leukemia patients treated with imatinib mesylate. Cancer Genet 205: 205: 563-571, 2012.

10. Fabarius A, Kalmanti L, Dietz CT, Lauseker M, Rinaldetti S, Haferlach C, Göhring G, Schlegelberger B, Jotterand M, Hanfstein B, et al: Impact of unbalanced minor route versus major route karyotypes at diagnosis on prognosis of CML. Ann Hematol 94: 2015-2024, 2015.
11. Kantarjian H, Shah NP, Hochhaus A, Cortes J, Shah S, Ayala M, Moiraghi B, Shen Z, Mayer J, Pasquini R, et al: Dasatinib versus imatinib in newly diagnosed chronic-phase chronic myeloid leukemia. N Engl J Med 362: 2260-2270, 2010.

12. Saglio G, Kim DW, Issaragrisil S, le Coutre P, Etienne G, Lobo C, Pasquini R, Clark RE, Hochhaus A, Hughes TP, et al: Nilotinib versus imatinib for newly diagnosed chronic myeloid leukemia. N Engl J Med 362: 2251-2259, 2010.

13. Iriyama N, Tokuhira M, Takaku T, Sato E, Ishikawa M, Nakazato T, Sugimoto KJ, Fujita H, Fujioka I, Hatta Y, et al: Incidences and outcomes of therapy-related chronic myeloid leukemia in the era of tyrosine kinase inhibitors: Surveillance of the CML Cooperative Study Group. Leuk Res 54: 55-58, 2017.

14. Cross NC, White HE, Müller MC, Saglio G, Hochhaus A: Standardized definitions of molecular response in chronic myeloid leukemia. Leukemia 26: 2172-2175, 2012.

15. Nakamae H, Yoshida C, Miyata Y, Hidaka M, Uike N, Koga D, Sogabe T, Matsumura I, Kanakura Y and Naoe T: A new diagnostic kit, ODK-1201, for the quantitation of low major BCR-ABL mRNA level in chronic myeloid leukemia: Correlation of quantitation with major BCR-ABL mRNA kits. Int J Hematol 102: 304-311, 2015.

16. Kanda Y: Investigation of the freely available easy-to-use software 'EZR' for medical statistics. Bone Marrow Transplant 48: 452-458, 2013.

17. Nakazato T, Iriyama N, Tokuhira M, Ishikawa M, Sato E, Takaku T, Sugimoto KJ, Fujita H, Fujioka I, Kimura Y, et al: Incidence and outcome of second malignancies in patients with chronic myeloid leukemia during treatment with tyrosine kinase inhibitors. Med Oncol 35: 99, 2018.

18. Sasaki K, Kantarjian HM, O'Brien S, Ravandi F, Konopleva M, Borthakur G, Garcia-Manero G, Wierda WG, Daver N, Ferrajoli A, et al: Incidence of second malignancies in patients with chronic myeloid leukemia in the era of tyrosine kinase inhibitors. Int J Hematol 109: 545-552, 2019.

19. Sasaki K, Kantarjian H, O'Brien S, Ravandi F, Konopleva M, Borthakur G, Garcia-Manero G, Wierda W, Daver N, Ferrajoli A, et al: Prediction for sustained deep molecular response of BCR-ABL1 levels in patients with chronic myeloid leukemia in chronic phase. Cancer 124: 1160-1168, 2018.

20. Sato E, Iriyama N, Tokuhira M, Takaku T, Ishikawa M, Nakazato T, Sugimoto KJ, Fujita H, Fujioka I, Asou N, et al: Introduction of second-generation tyrosine kinase inhibitors may reduce the prognostic impact of high-risk patients, according to the European treatment and outcome study (EUTOS) score. Leuk Lymphoma 59: 1105-1112, 2018.

21. Alhuraiji A, Kantarjian H, Boddu P, Ravandi F, Borthakur G, DiNardo C, Daver N, Kadia T, Pemmaraju N, Pierce S, et al: Prognostic significance of additional chromosomal abnormalities at the time of diagnosis in patients with chronic myeloid leukemia treated with frontline tyrosine kinase inhibitors. Am J Hematol 93: 84-90, 2018.

22. Fujioka I, Takaku T, Iriyama N, Tokuhira M, Kimura Y, Sato E, Ishikawa M, Nakazato T, Sugimoto KJ, Fujita H, et al: Features of vascular adverse events in Japanese patients with chronic myeloid leukemia treated with tyrosine kinase inhibitors: A retrospective study of the CML Cooperative Study Group database. Ann Hematol 97: 2081-2088, 2018.

23. Fabarius A, Duesberg P, Giehl M, Seifarth W, Hochhaus A and Hehlmann R: Genomic instability in context of the chromosomal theory. Cell Oncol 30: 503-504, 2008.

24. Melo JV and Barnes DJ: Chronic myeloid leukaemia as a model of disease evolution in human cancer. Nat Rev Cancer 7: 441-453, 2007.

25. Skorski T: Genetic mechanisms of chronic myeloid leukemia blastic transformation. Curr Hematol Malig Rep 7: 87-93, 2012. 